\title{
Grußwort von Hermann-Josef Pelgrim, Oberbürgermeister der Stadt Schwäbisch Hall
}

Es freut mich sehr, dass wir heute in der Kultur- und Reformationsstadt Schwäbisch Hall eine Tagung eröffnen können, zu der eine hochkarätige Delegation aus Slowenien gekommen ist. Bei dieser Tagung zur Reformation in Hall erinnern wir auch an den slowenischen Reformator Primus Truber, der das Fundament zur slowenischen Sprache gelegt hat, und zwar hier in unserer Stadt.

Vermutlich werden sich viele die Frage stellen: Wie kam Truber nach Hall und warum druckte er ausgerechnet hier seine ersten Bücher in windischer Sprache, wie bei uns damals Slowenisch bezeichnet wurde?

Es war das Zeitalter der Reformation, genauer gesagt, während ihrer größten Krise. Als Reformator wurde Truber 1548 aus seiner Heimat vertrieben. Er fand in Rothenburg ob der Tauber Zuflucht. Übrigens musste zur selben Zeit auch Johannes Brenz aus Hall fliehen. Der Grund dafür: Kaiser Karl V. hatte in diesem Jahr versucht, die Lösung aller religiösen Probleme im Reich weitgehend im katholischen Sinn zu erzwingen. Die bisherigen Reformen wurden kurzerhand rückgängig gemacht und die alte katholische Ordnung allen Untertanen aufgezwungen. Man spricht vom Augsburger Interim. Brenz lehnte sich dagegen auf und musste schließlich, um seiner Verhaftung zu entgehen, Hals über Kopf aus Hall fliehen. Zwar fügte sich Hall dem Willen des Kaisers, aber in großen Teilen der Bevölkerung und der Stadtregierung nur sehr widerwillig und bald auch protestierend, bedeuteten doch die Maßnahmen eine absolute politische Bevormundung der Reichsstadt.

Die beiden Bücher Trubers wurden also im Untergrund gedruckt. Er selbst berichtet rückblickend, man habe ihm geraten, die beiden Werke drucken zu lassen, um damit dem einfältigen windischen Volk viel Gutes zu schaffen. Er habe sie verbotenerweise drucken lassen: Ich habe es verborgen und unter Gefahr getan. Der Buchdrucker und ein christlicher Prediger, die beide kein Wort windisch sprachen, überwachten den Druck und übernahmen die Korrektur. In einem anderen Brief erwähnt Truber explizit Schwäbisch Hall als Druckort.

Dennoch dachte man lange Zeit, die Werke seien in Tübingen gedruckt worden, wo auch schon vor einigen Jahren eine Erinnerungstafel an einem Gebäude angebracht wurde. Nun muss sie abgehängt werden. Denn auf Grund der Buchstabentypen konnte eindeutig nachgewiesen werden, dass der Katechismus und das 
Abecedarium in Hall gedruckt wurden (der Nachweis ist etwa so aussagekräftig wie in der Kriminalistik die Übereinstimmung von Fingerabdrücken). Der in den Briefen genannte Prediger, der half, war sicher nicht Brenz, denn dieser war ja bereits aus Hall geflohen. Vermutlich war es einer seiner Haller Pfarrerkollegen von St. Michael oder St. Katharina, die in Hall geblieben waren, und engstens vertraut waren mit Brenz. Der Kontakt von Truber zu Hall war gewiss über Brenz zustande gekommen, dessen Katechismus den von Truber beeinflusste.

Das erste Buch in slowenischer Sprache hat für Slowenien eine ähnliche Bedeutung wie die Übersetzung der Bibel für Deutschland: nämlich jeweils die Grundlage für die geregelte Hochsprache.

Für Slowenien ist die Bedeutung aber insofern nochmals anders, als der Staat noch jung ist, erst 1991 trat er aus dem Verband Jugoslawiens aus. Diese Schriften belegen, dass die slowenische Kultur viel weiter zurückreicht. Die eigenständige slowenische Schriftsprache manifestierte sich - schwarz auf weiß - vor mehr als 460 Jahren hier in Schwäbisch Hall.

Geschichte kann spannend sein und Jahrhunderte zurückreichende Ereignisse werfen ihren Schatten oder ihr Licht bis in die Gegenwart.

Ich möchte Ihnen, sehr geehrte Frau Botschafterin, und Ihrer Delegation herzlich für Ihren Besuch danken. Danken möchte ich auch Ihnen, liebe Frau Weber, dass wir für diesen wichtigen Abend das gepflegte Ambiente der Kunsthalle nutzen dürfen. Mein besonderer Dank gilt den Organisatoren der Tagung, allen voran dem Historischen Verein für Württembergisch Franken und dem Hällisch-Fränkischen Museum sowie dem evangelischen Dekanat Schwäbisch Hall.

Der Tagung wünsche ich viel Erfolg, und ich bin schon gespannt auf den Tagungsband, der im Anschluss gedruckt werden soll. 